\title{
Respiratory failure caused by intrathoracic amoebiasis
}

This article was published in the following Dove Press journal:

Infection and Drug Resistance

10 March 2010

Number of times this article has been viewed

\section{Toshinobu Yokoyama' \\ Masashi Hirokawa' \\ Yutaka Imamura ${ }^{2}$ \\ Hisamichi Aizawa' \\ 'Division of Respirology, Neurology and Rheumatology, Department of Internal Medicine, Kurume University, Japan; ${ }^{2}$ Department of Hematology, St. Mary's Hospital, Kurume, Japan}

\begin{abstract}
A 41-year-old male was admitted to the hospital with symptoms of diarrhea, fever and rapidly progressive respiratory distress. A chest radiograph and computed tomography (CT) of the chest and the abdomen showed a large amount of right pleural effusion and a large liver abscess. The patient was thus diagnosed to have amoebic colitis, amoebic liver abscess and amoebic empyema complicated with an HIV infection. The patient demonstrated agranulocytosis caused by the administration of trimethoprim-sulfamethoxazole. However, the administration of granulocyte colony-stimulating factor made it possible for the patient to successfully recover from agranulocytosis, and he thereafter demonstrated a good clinical course.
\end{abstract}

Keywords: amebiasis, amoebic empyema, HIV, agranulocytosis, trimethoprim-sulfamethoxazole

\section{Introduction}

Recently, the number of newly diagnosed patients with HIV infection is increasing in Japan and eastern Asia (even though it is decreasing in most Western countries) while amebiasis is also increasing in Japan as a sexually transmitted disease, especially among males who admit to having sex with men (MSM). There is also a high frequency of asymptomatic Entamoeba histolytica infection, especially among MSM. Amebiasis is characterized by diarrhea and it sometimes induces the development of liver abscesses as a complication with amebic colitis. ${ }^{1}$ Pleural empyema is rare as a complication in cases of amebiasis. Trimethoprim-sulfamethoxazole is often administered to patients with an HIV infection to prevent pneumocystis pneumonia. Unfortunately, trimethoprim-sulfamethoxazole may also induce agranulocytosis in patients with an HIV infection, thus leading to the development of severe infectious diseases.

\section{Case report}

A 41-year-old male was admitted to the hospital with symptoms of diarrhea, fever, dyspnea and right pleural effusion. The illness began in the latter part of August 2008, initially presenting with diarrhea and fever. He was an MSM and the serology for HIV antibody was positive. He had no history of traveling abroad, alcoholism, any medication or intravenous drug use. His vital signs on admission were; conscious, blood pressure $95 / 60 \mathrm{mmHg}$, pulse late 146 beats/min, respiration, 45 breaths/min, saturation $\mathrm{O}_{2}$ (room air), $88 \%$ and body temperature $39^{\circ} \mathrm{C}$. The notable findings of a physical examination included emaciation (BMI 16.1), oral candidasis and decreased breath sounds on the right side of his chest. A chest radiograph and computed tomography (CT) of the chest showed a large amount of right pleural effusion (Figure 1). A CT scan of the abdomen detected large liver abscess (Figure 2). The laboratory data included submit your manuscript | www.dovepress.com

Dovepress 


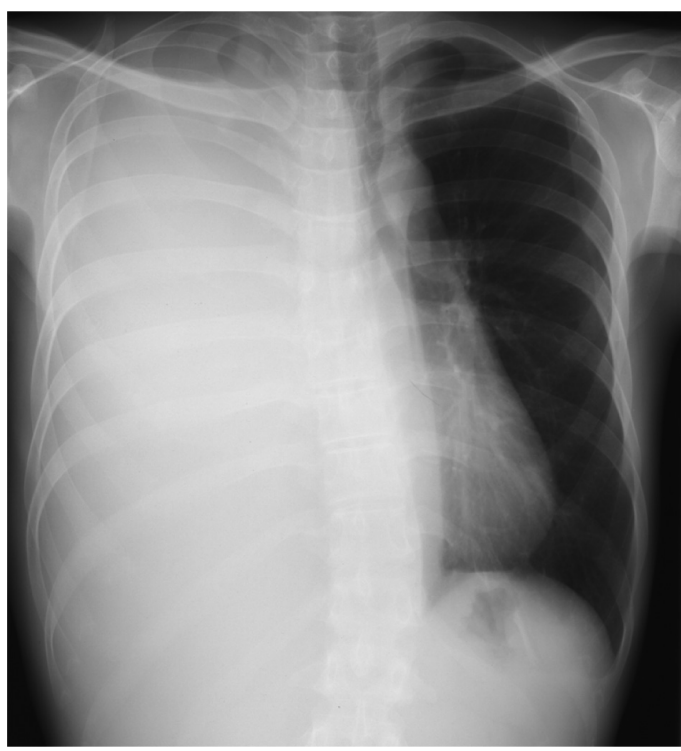

Figure I Chest radiography showing complete opacity of the right lung with a shifted mediastinum to the left.

a leukocyte count of $10,320 / \mu \mathrm{L}$ with $89 \%$ neutrophils, $8 \%$ lymphocytes, $3 \%$ monocytes, hemoglobin $8.8 \mathrm{~g} / \mathrm{dL}$, C-reactive protein $23.6 \mathrm{mg} / \mathrm{dL}$, aspirate aminotransferase $95 \mathrm{U} / \mathrm{L}$, alanine aminotransferase $74 \mathrm{U} / \mathrm{L}$, alkaline phosphatase $478 \mathrm{U} / \mathrm{L}, \gamma$-glutamyl transpeptidase $134 \mathrm{U} / \mathrm{L}$, albumin $2.1 \mathrm{~g} / \mathrm{dL}$, total cholesterol $57 \mathrm{mg} / \mathrm{dL}$, blood urea nitrogen $18.4 \mathrm{mg} / \mathrm{dL}$, creatine $0.57 \mathrm{mg} / \mathrm{dL}$ and hyponatremia $(123 \mathrm{mEq} / \mathrm{L})$. The findings of human immunodeficiency virus type 1 antibody tests were positive for enzyme immunoassays (EIA) and also based on the Western blot method. Thoracentesis revealed milk chocolate or café au lait colored pleural fluid (Figure 3). In an examination of the pleural fluid,

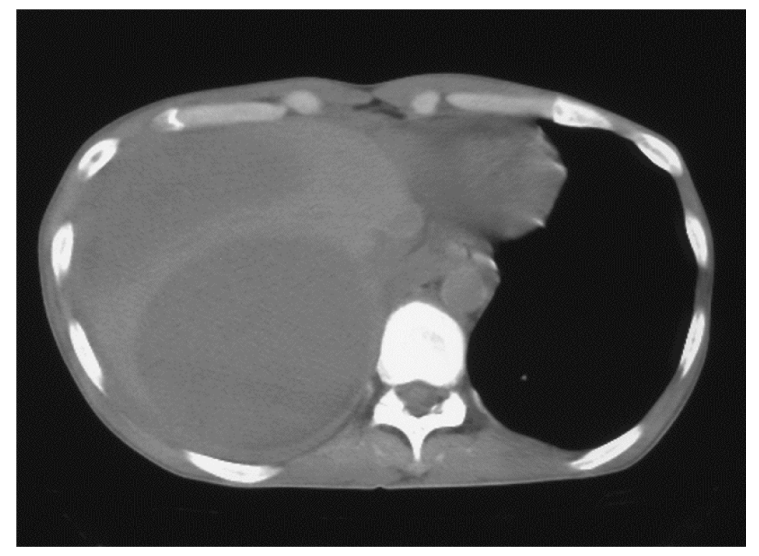

Figure 2 Computed tomography (CT) of the abdomen showing a large liver abscess. cytology, bacterial culture, smear and polymerase chain reaction to detect Mycobacterium tuberculosis DNA were negative, the adenosine deaminase activity was $240 \mathrm{IU} / \mathrm{L}$. The pleural fluid showed a cell count of $40125 / \mathrm{mL}$ (74.3\% neutrocytes, $25.7 \%$ monocytes). Other examinations of the laboratory findings detected cysts of Entamoeba histolytica in the patient's stool. The CD4 lymphocyte count in the peripheral blood was $179 / \mu \mathrm{L}$ (repeated counts for CD4 lymphocytes ranged from 286 to $359 / \mu \mathrm{L}$ ) and the amount of HIV-RNA was 3700 copies/ $\mu \mathrm{L}$ (repeated counts for HIVRNA ranged from 43,000 to 90,000 copies $/ \mathrm{mL}$ ). Although E. histolytica was not identified from the pleural fluid, antibodies (fluorescence antibody technique) against E. histolytica were demonstrated in the serum $(200 \times)$. The patient was thus diagnosed to have amoebic colitis, amoebic liver abscess and amoebic empyema complicated with an HIV infection. The right side pleural effusion was drained using a chest tube and he was administered metronidazole ( $2250 \mathrm{mg}$ /day) orally for 28 days in total. A large volume of pus was drained from the right thoracic space. A small volume remained. The right lung was re-expanded. His fever, dyspnea and general condition significantly improved thereafter. The patient was therefore administered trimethoprimsulfamethoxazole to prevent pneumocystis pneumonia and itraconazole to prevent fungal infections. However, he developed agranulocytosis 22 days after administration. The absolute neutrophil count was $0 / \mu \mathrm{L}$. Agranulocytosis in this case was therefore considered to have been caused by the administration of trimethoprim-sulfamethoxazole. After the discontinuation of trimethoprim-sulfamethoxazole, the recombinant human granulocyte colony-stimulating factor (G-CSF) drug filgrastim was administered daily at a dose of $200 \mu \mathrm{g} / \mathrm{m}^{2}$ intravenously. Following 4 days of treatment with G-CSF, the patient's absolute neutrophil count was above $9 / \mu \mathrm{L}$, while after 7 days of treatment it was $2990 / \mu \mathrm{L}$ (white blood cell count $4600 / \mu \mathrm{L}$, neutrophils $65 \%$ ). The patient did not demonstrate any further infection during the clinical course. He was discharged 45 days after admission.

\section{Discussion}

Amebiasis may become invasive depending on various host immune factors, especially in patients with an HIV infection. ${ }^{2}$ Three to $9 \%$ of patients with amoebic colitis develop amoebic liver abscess ${ }^{3}$ and furthermore $7 \%$ to $20 \%$ of amoebic liver abscess develop amoebic empyema. ${ }^{4,5}$ However, about a third of all cases of pleuropulmonary amebic disease demonstrate the presence of exudative or serous, reactive pleural effusion. ${ }^{6,7}$ This means that some of intrathoracic complications 


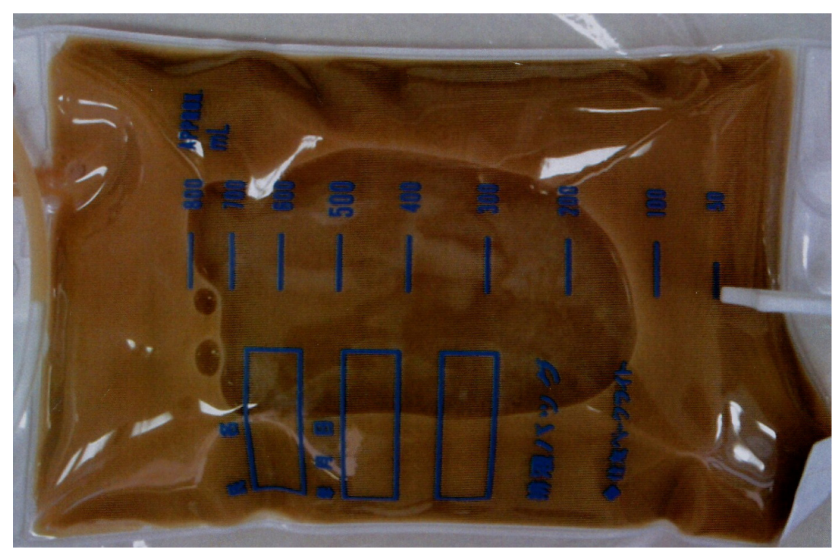

Figure 3 The features of the pleural fluid showing a milk-chocolate brown or café au lait color.

of amebiasis are thus included reactive pleural effusion other than amoebic empyema. Some mechanisms of amoebic empyema have been previously described. For example, a rupture of an amoebic liver abscess into the pleural space through the diaphragm, hepatobronchial fistula, lymphatic spread, hematogenous spread from the primary intestinal lesion have all been reported. ${ }^{6-8}$ The most common pathogenetic mechanism of pleural amebic empyema is that the liver abscess advances to and across the diaphragm or bursts into the right pleural space. In this case, there was no hepato-bronchial fistula, no sign of lymphatic spread and no perihepatic ascites detected by $\mathrm{CT}$, thus indicating that there was no rupture of a liver abscess. Amoebic empyema was suggested to occur by extension or inflammatory invasion of an amoebic liver abscess directly into the pleural cavity.

The detection of E. histolytica from pleural fluid is rare in the diagnosis of amoebic empyema. Amebas are detected in less than $10 \%$ of cases. ${ }^{5}$ The diagnosis of amoebic empyema is made by the identification of antibodies against $E$. histolytica in the serum, and a negative bacterial culture of the pleural fluid. The color of the pus aspirated from amoebic liver abscesses also tends to be described as chocolate brown or anchovy-sauce color in the literature. ${ }^{6}$ However, the features of amoebic empyema remain to be fully elucidated. The color of the pleural fluid in the current case was noteworthy. It was different from usual bacterial empyema. Furthermore, the pleural fluid in this case did not have a foul odor, although most pleural fluid specimens with bacterial empyema tend to have a foul odor because the majority of empyema are caused by anaerobes. The color and smell of the pleural fluid may therefore be a unique diagnostic feature of amoebic empyema and may thus be helpful in making a differential diagnosis to distinguish common bacterial empyema from amoebic empyema.
The administration of trimethoprim-sulfamethoxazole to prevent pneumocystis pneumonia is common in the management of patients with HIV infection. Therefore, trimethoprimsulfamethoxazole was administered after diagnosing the patient to have an HIV infection. Agranulocytosis in this case was supposed to be due to trimethoprim-sulfamethoxazole. Although agranulocytosis is a potentially life-threatening condition, especially under conditions of severe amebiasis, the patient was able to successfully recover after the administration of G-CSF and oral metronidazole. Trimethoprim-sulfamethoxazole is known to sometimes induce agranulocytosis as a side effect. As a result, an increasing number of such cases are expected in the future because many patients with HIV infection require the administration of trimethoprim-sulfamethoxazole in order to prevent pneumocystis pneumonia, and the occurrence of amebiasis is also increasing. This case is therefore considered to be an instructive case for clinicians.

The management of amoebic empyema in most cases involves the administration of parenteral metronidazole, ${ }^{9}$ followed by drainage. Metronidazole was administered orally in the current patient, followed by drainage, and this yielded a good outcome. The incidence of amebiasis is not as high in AIDS patients as in HIV-seronegative patients. ${ }^{10}$

However, whether risk of invasive amebiasis is higher among HIV-infected persons than uninfected persons remains. Hung and coworkers described persons infected with HIV are at an increased risk for invasive amebiasis. ${ }^{2,1}$ Furthermore the epidemiology demonstrated that invasive amebiasis occurs much more frequently in Taiwan than reported in Western countries. Interestingly, amebiasis is a relatively common parasitic disease at a time when CD4 counts are relatively high in Taiwan in comparison to Western countries. ${ }^{2,11}$ Extraintestinal amebiasis is also treated by metronidazole, even in AIDS patients who have low CD4 cell counts and receiving anti-HIV drugs. ${ }^{8,11,12}$ The estimated mean survival is not significantly different between the HIV-infected patients with and without invasive amebiasis. ${ }^{11}$ Even though the population of newly diagnosed patients with HIV infection is decreasing in most Western countries, the number is, in contrast, increasing in Japan, Korea, Hong Kong and Taiwan. In addition, the occurrence of invasive amebiasis is therefore also expected to increase in these countries.

\section{Disclosures}

The authors disclose no conflicts of interest. 


\section{References}

1. Mitarai S, Nagai H, Satoh K, Hebisawa A, Shishido H. Amebiasis in Japanese homosexual men with human immunodeficiency virus infection. Intern Med. 2001;40(7):563-564.

2. Hung CC, Deng HY, Hsiao WH, et al. Invasive amebiasis as an emerging parasitic disease in patients with human immunodeficiency virus type 1 infection in Taiwan. Arch Intern Med. 2005;165(4):409-415.

3. Barbour GL, Juniper K. A clinical comparison of amebic and pyogenic abscess of the liver in 66 patients. Am J Med. 1972;53(3):323-334.

4. Stanley SL Jr. Amoebiasis. Lancet. 2003;361(9362):1025-1034.

5. Ibarra-Pérez $\mathrm{C}$. Thoracic complications of amebic abscess of the liver: report of 501 cases. Chest. 1981;79(6):672-677.

6. Adeyemo AO, Aderounmu A. Intrathoracic complication of amoebic liver abscess. J Royal Society of Med. 1984;77(1):17-21.
7. Kubitschek KR, Peters J, Nickeson D, Musher DM. Amebiasis presenting as pleuropulmonary disease. West J Med. 1985;142(2):203-207.

8. Shamsuzzaman SM, Hashiguchi Y. Thoracic amebiasis. Clin Chest Med. 2002;23(2):479-492.

9. Cameron EW. The treatment of pleuropulmonary amebiasis with metronidazole. Chest. 1978;73(5):647-650.

10. Lowther SA, Dworkin MS, Hanson DL. Entamoeba histolytica/ Entamoeba dispar infections in human immunodeficiency virus-infected patients in the United States. Clin Infect Dis. 2000;30(6):955-959.

11. Hung CC, Chen PJ, Hsieh SM, et al. Invasive amoebiasis: an emerging parasitic isease in patients infected with HIV in an area endemic for amoebic infection. AIDS. 1999;13(17):2421-2428.

12. Ohnishi K, Kimura K. Amebic liver abscess in an elderly AIDS patient. Southeast Asian J Trop Med Public Health. 1999;30(3):594-595.

\section{Publish your work in this journal}

Infection and Drug Resistance is an international, peer-reviewed openaccess journal that focuses on the optimal treatment of infection (bacterial, fungal and viral) and the development and institution of preventive strategies to minimize the development and spread of resistance. The journal is specifically concerned with the epidemiology of antibiotic

\section{Dovepress}

resistance and the mechanisms of resistance development and diffusion in both hospitals and the community. The manuscript management system is completely online and includes a very quick and fair peerreview system, which is all easy to use. Visit http://www.dovepress.com/ testimonials.php to read real quotes from published authors. 